\title{
Guerra fría y distensión en América Latina*
}

\author{
A la luz de los ensayos de don \\ José Medina Echavarría
}

\section{Glosario del esquema analítico DEL PROFESOR MEDINA ECHAVARRIA.}

Los trabajos principales de don José en los últimos años versaron sobre el escenario internacional. Los problemas de la paz, de la guerra fría y la distensión, del porvenir de la democracia en el mundo occidental, de las propuestas y visiones respecto al nuevo orden internacional, fueron - entre otros muchos afines- escarmenados con la erudición, creatividad y discreción ideológica características de su personalidad y obras ${ }^{1}$.

Huelga excusarnos por no tratar de abarcar todo ese espectro. Nos concentraremos solamente en su ensayo más extenso y comprensivo (América Latina en los escenarios posibles de la distensión), sin intentar recapitular su búsqueda y hallazgos — tarea también imposible. Apenas queremos relevar algunas de sus ideas básicas sobre guerra fría y distensión para aventurarnos después en algunas proyecciones de esos fenómenos sobre el cuadro latinoamericano- siguiendo con ésto uno de los hábitos del maestro español.

Se me perdonará que comience con un testimonio personal. Recuerdo hasta hoy las primeras reuniones -informales y restringidas-que se efectuaron en la GEPAL para escuchar los planteamientos de don

*Trabajo presentado en el seminario realizado en Madrid (30 de junio - 2 de julio, 1980) en homenaje a don José Medina Echavarría y patrocinado por el Instituto de Cooperación Iberoamericana y la CEPAL. Las opiniones vertidas en este documento son de la exclusiva responsabilidad del autor. Este trabajo forma parte de un conjunto de artículos dedicado en lo fundamental a recoridar las principales contribuciones de don José Medina Echavarría en el campo de las ciencias sociales. Su propósito es examinar el agitado y cambiante contrapunto entre los reflejos del pleito inter-potencias y el desarrollo general latinoamericano en los períodos clasificados como de guerra fría y distensión.

${ }^{1}$ Entre ellos destacamos: "América Latína en los escenarios posibles de la distensión", Revista de la CEPAL, $\mathrm{N}^{\circ}$ 2, Segundo Semestre, 1966; "Apuntes acerca del futuro de las democracias occidentales", Revista de la CEPAL, N ${ }^{\circ}$ 4, Segundo Semestre, 1977; "Las perspectivas de un nuevo orden económico internacional en perspectiva", El Trimestre Económico, $N^{\circ} 179$, julio-septiembre, 1978, México. 
José. Y no he olvidado la profunda impresión que me causaron y el grado en que ampliaron y modificaron mi horizonte en la materia.

Esto no es extraño dada la calidad de ese trabajo, pero sí vale puntualizar que esa fue la reacción de alguien que prácticamente vivió la mayor parte de sus años de adulto dentro del contexto de la guerra fría -y no sólo de una manera pasiva ${ }^{2}$. Pero tal vez nos habíamos acostumbrado de tal manera a su ingrata atmósfera y condicionamiento que habíamos pasado a considerarla como "algo dado", que no justificaba mayor análisis crítico. Las ideas de don José resultaron un fermento y una guía para enmendar ese gran descuido. Me permitiré recordar algunas de ellas — sabiendo que algunos ya las conocen, pero que otros pueden ser incentivados a hacerlo. La selección, por cierto, deja fuera del tiesto muchas otras de gran importancia. Por otra parte, haciéndole poca justicia, sólo podremos recurrir al método de "párrafos marcados".

Las primeras tienen que ver con su apreciación de la crisis actual -antecedente meridiano de las preocupaciones sobre los temas específicos elegidos.

Nos encontramos, según él, "al final de una era, en la terminación problemática de la estructura forjada en la postguerra, pasado inmediato y realidad todavía presente al mismo tiempo", existiendo la "convicción de que todos los problemas de nuestro tiempo vuelven a depender en última instancia de cómo se logre y perfeccione la organización de la paz mundial". Así, "parece ser un hecho la escasa viabilidad de la continuación de la estructura de la paz conseguida en la inmediata postguerra y de que se impone por éso comenzar con renovado ímpetu la construcción de otra".

Frente a ese cuadro discierne dos criterios polares, que es interesante exponer por su lucidez y precisión. Al presentarlos explica que "no podrá extrañarnos de que situación semejante, denominada en definitiva por una conciencia de crisis, sea también un tiempo de extremos... por un lado, de una visión pesimista de ocaso y en su lado opuesto la construcción utópica de un futuro optimista: la oscilación pendular... típica de la 'futurología' contemporánea. En un extremo tenemos ahora la renovación de una tonalidad spengleriana que no se limita a la decadencia de occidente sino que ábarca la civilización del mundo entero y que si exhibe por un lado cultivadores de la interpretación histórica, comprende por otro representantes del más puro.'ciencismo'

${ }^{2} \mathrm{Mi}$ generación -aunque en su tiempo mozo - vivió con mayor plenitud la "otra guerra", particularmente por su sentido - simbólico y real一 antifascista y democrático, lo que nos dejó huellas imperecederas. 
positivista. Frente a los augurios de siniestros más o menos graves, próximos o lejanos, circulan también hoy entre nosotros como su extremo opuesto todos los que son portadores de un aliento utópico".

Pero al maestro no le interesa tanto contrapesar esas visiones o formular otra. Su interés primordial es tranquilamente pragmático: "Más que lo que debemos hacer interesa realmente aquello que "podemos hacer' en los años venideros". Y a este propósito dedica muchas páginas fecundas que escapan a la órbita limitada de nuestro trabajo.

El segundo tema que deseo privilegiar es su concepción de la guerra fría. Al respecto me limitaré a reproducir dos formulaciones notables.

Dice en una parte que "sólo es posible trazar cabalmente algunos de los rasgos más característicos de esa extraña forma de convivencia general que cubre un período aproximado de veinte años, de 1948 a 1968: la nitidez con que se percibe por unos y otros, el común silencio sobre el significado de los peligros de una 'guerra total', la inflexibilidad en los sistemas de ideas en que se apoyaba y la tremenda paradoja de las consecuencias económicas en la forma de un crecimiento acogido con el mayor entusiasmo".

La articulación de la guerra fría es en efecto un fenómeno que se ofrece y se capta con la máxima claridad. Y lo mismo por los protagonistas principales como por parte de terceros. Se origina una situación en que, como en la duradera estratificación social del Ancien Régime, todos conocen perfectamente el puesto que les corresponde y que de hecho ocupan. Todas las formas de conducta internas o externas, nacionales e internacionales, sólo existen y son comprendidas como evidentes en función del antagonismo fatalmente planteado. Hasta el punto de que cuando en ciertos años algunos se definen como no alineados no necesitan declarar su sentido ni preguntarse en qué consiste el abandono de la fila. La nitidez en el enfrentamiento de dos superpotencias lleva consigo idéntica claridad o ausencia de dudas en las posiciones de aliados y satélites, aunque a veces entre los últimos no sean ni queridas ni buscadas. Por eso debe tenerse muy en cuenta la expresión lineal de los perfiles en la estructura sociopolítica de la guerra fría para comprender de inmediato las confusiones que se producen cuando el intento de su eliminación o apaciguamiento tolera la introducción del claroscuro en la pintura de sus rasgos".

En otro lado, subraya estos conceptos, abriendo paso al examen de la distensión: "La estructura de la guerra fría, con su limitación rigurosa del enemigo y de las doctrinas antagónicas, fijaba al mismo tiempo el ámbito de las contraposiciones internas, de lo tolerable tanto como de lo inadmisible. El juego de las ideas y de las organizaciones políticas estaba demarcado por el peligro que la presencia del enemigo significa- 
ba. Una manifestación concreta de venerables proposiciones sociológicas acerca de las relaciones entre el grupo propio y grupo ajeno. Las alteraciones en la figura del grupo de referencia ajeno inciden en la naturaleza y tipo de la cohesión del primero. En la medida en que los protagonistas de la guerra fría se encuentran liberados de las constricciones que imponía su rígida estructura, se sienten por el contrario obligados a encontrar nuevas maneras de consenso. La fórmula de la búsqueda de una nueva identidad no es otra que la de la preocupación por encontrar un nuevo consenso político. El proceso y más aún el pleno logro de la distensión implica una crisis generalizada de ese consenso en la forma vigente durante muchos años"

Al entrar a considerar los planteamientos de don José sobre la distensión no se puede dejar de mencionar algo obvio: que estamos viviendo una coyuntura álgida de tensiones internacionales. Alguien podría pensar que ello despoja de toda actualidad a las reflexiones sobre la materia. Pero el autor es demasiado sabio para no haber considerado estas posibilidades con anticipación y cautela, como puede apreciarse en esta reflexión: "La détente, urge repetirlo, se ha considerado en su doble calidad de proceso en marcha y de meta que merece la pena de ser perseguida. Quizá esta última no se consiga nunca. Nadie puede saberlo con certeza. Lo único cierto y visible es que el proceso mismo no sigue una línea recta, pues avanza y retrocede, da tantos pasos en falso como otros acertados y en definitiva ofrece por hoy una marcha sinuosa. El espectador que sigue su curso en la prensa diaria o en el comentario de intención científica de distintas revistas, mạ́s de una vez deja de tocar fondo, braceando desesperado en el escepticismo. Se requiere para evitar semejante naufragio tomar la razonable distancia del saber científico y contar con la paciencia necesaria para contemplar los acontecimientos sin premuras durante un lapso de tiempo no menos razonable. Nadie puede asegurar el fin de la aventura, su happy end; pero éste es el riesgo que hay que aceptar si se quiere lograr un mínimo de previsión frente a la posibilidad de acciones prácticas, de políticas concretas que respondan a una moral de responsabilidad. La cual exige la ponderación racional mayor posible de los resultados directos, indirectos y secundarios de toda acción".

Esta aclaración nos permite seguir con dos aspectos que nos parecen esenciales en el análisis del maestro: su concepto de la distensión y las variedades de la misma que distingue.

Respecto al primero, considérese este juicio: "La distensión en el sentido específico objeto de la consideración de estas páginas no es ningún enigma incomprensible en la opinión pública actual. Todos saben en principio de qué se trata: que pueda darse un aflojamiento en. 
las relaciones de poder entre las grandes potencias, que aminore las fuertes tensiones que entre ellas existen y que todos los demás sufren como reflejo en alguna medida. Puede ser el momento de un respiro o el comienzo de una prolongada seguridad común. Sin embargo, sobre esta significación general pesa como simbólico infortunio la equivocidad originaria del vocablo francés que se utiliza con general aceptación. Pues la détente, derivada del détentre, significó también en su originaria semántica el acto de destendie la ballesta, un instrumento de combate. Esa primitiva ambigüedad, suficiente para comprender las actitudes contradictorias que despierta la posibilidad concreta de la distensión, sigue gravitando en otras formas hasta hoy".

En cuanto a las modalidades de la distensión, después de reiterar que su "marcha todavía indecisa hoy... tambaleante al parecer en más de un momento, permite presumir su configuración en tres posibles formas, otros tantos escenarios de un futuro inmediato que interesa a todos por igual, aparte de sus principales protagonistas".

Ellas son la cooperativa, la competitiva y la conflictiva, síntesis felices de las posibilidades latentes - aunque no inminentes o de necesaria materialización.

La distensión cooperativa "representa el escenario en que la misma alcanza su plena madurez y consolidación", que podría significar principalmente tendencias hacia la "desatelización". Esto es, una mayor flexibilidad en "el comportamiento internacional de unos y otros, sin que exista amenaza de inmediatos conflictos" y hacia una "descentralización ideológica", entendida como "una liberación del constreñimiento imperioso de los dos grandes sistemas ideológicos".

En este segundo plano, vale la pena destacar su referencia al "escape al temor del tabú de la reforma... que han mantenido muchos en los años recientes por la existencia de ideologías con idénticas presunciones de verdad absoluta. Poniéndose, en consecuencia, en olvido todo lo que en la historia se ha debido al escalonamiento paciente de sucesivas reformas oportunas, que si carecen por sí mismas del halo luminoso de las grandes fórmulas radicales, capaces ciertamente de movilizar grandes esfuerzos, no tienen que pagarse sin embargo con dosis cuantiosas de sacrificio y sufrimiento".

Una aguda y elocuente legitimación de la inclinación reformista, sin duda, que no implica obligadamente el rechazo de las opciones revolucionarias allí donde, manifiestamente, están clausuradas las vías para todo cambio progresivo ${ }^{3}$. Claro está, siempre habrá polémica respecto

${ }^{3} \mathrm{El}$ "derecho a la rebelión" es compartido - dentro de sus particulares concepciones- por las tradiciones cristiana, liberal y marxista, como bien se sabe. 
a la interpretación de esas situaciones, pero ello no disminuye la validez del criterio expuesto por don José.

La distensión competitizia "constituye la simple prolongación de las circunstancias actualmente vividas", según el autor. Y lo será "en la medida en que los conflictos y tensiones que contenga se encuentren sometidos o encubiertos... por cierto número de principios y aspiraciones comunes, sea que provengan de idénticas convicciones o de intereses egoístas paralelos".

Dentro de esta misma categoría resalta la vinculación que se establece con los problemas del Tercer Mundo: "En la medida que permanezca sin resolverse la tensión horizontal entre los grandes centros de mayor riqueza - la tensión fundamental entre el este y el ỏeste- no podrá menos que acentuarse la tensión vertical entre Norte y Sur, entre los países ricos y los más pobres; acentuación que podrá darse, aparte de su gravedad innegable, como un medio incluso de táctica diplomática para desviar la atención por algún tiempo de la divergencia más decisiva de los grandes sistemas industriales".

El escenario conflictivo "no tanto se refiere a la existencia de conflictos, siempre posibles en cualquier circustancia, sino al grado mayor de su intensidad, al momento en que la cantidad se transforma en calidad, dando otra vez a los conflictos en juego un carácter total y absoluto. La conversión que renueva el terror de pasadas experiencias históricas".

De ahí, como se comprende, el regreso hacia el esquema pretérito y desembozado de guerra fría hay pocos pasos y, como señala el autor, "el holocauto nuclear es otra vez el mayor peligro de un callejón sin salida", pero él no quiere examinar esa posibilidad: le basta con "destacar el horror de esa desesperanzada perspectiva".

Estas referencias puntuales son terriblemente injustas para el rico y comprensivo tejido de las reflexiones del maestro. Lo destacado, empero, constituye un esquemá analítico y una sucesión de inspiraciones para la investigación concreta. Como él mismo señala, con su proverbial modestia, "sólo valen como el punto de partida de una paciente acumulación de análisis empíricos de tendencias reales, que ha de efectuarse al mismo tiempo en los más diversos campos y por distintos especialistas capaces de entenderse entre sí. Sin el apoyo de estudios concretos es imposible escapar de un plano especulativo".

Ya señalamos antes que no hay razón para pensar que las ideas del autor han sido contradichas por la evolución reciente del cuadro internacional o que pecan de utopismo, por bien intencionado y cauto que sea. En último término, sus consideraciones sobre la distensión envolvían objetivos bastantes modestos - aunque trascendentes, que él definió así: "Lo que todos los interesados y conocedores piden es tan sólo el 
logro de 'un modelo mínimo de paz' adecuado a los problemas de nuestro tiempo"; "la existencia... de una organización mundial de la paz en que aparezcan atenuadas, reciprocamente moderadas al menos, las desnudas relaciones de poderio que mantienen aún su obediencia a la ley de la selva en el escenario internacional".

Naturalmente, se podrá disentir y hasta rechazar los lineamientos trazados por don José, pero quienes lo hacen deberán cargar con el "peso de la prueba", esto es, la de formular otras opciones capaces de impedir aquel desenlace macabro. ${ }^{4}$

Sea como sea, su contribución seguirá distinguiéndose como una de las más valiosas y originales que se han hecho en materia tan vital y controvertida.

\author{
II. \\ AMÉRICA LATINA EN LOS ESCENARIOS DE LA \\ CILERRA FRÍA Y' LA DISIENSIÓN
}

Los trabajos recordados de don José tienen siempre presente la realidad latinoamericana, directa o indirectamente. El que hemos tomado de base incluye una sección titulada "La posición de América Latina en las condiciones de la distensión" y en ésas y otras páginas incursiona en temas tan candentes como los del "desarrollismo", la dependencia, las empresas internacionales, la integración regional, los estilos de desarrollo y otros.

Pero, como anticipamos, en esta parte no intentaremos glosar sus ideas sobre esas materias. Tomaremos, en cambio, como un trasfondo, el esquema analítico expuesto anteriormente para contrastarlo con la experiencia de la región, teniendo como hilo conductor el contrapunto entre las políticas de cambio - reformistas y revolucionarias- del statu quo y el marco externo (o hemisférico) en que se han desenvuelto. Traslucirá en ello algo de nuestra vivencia individual o generacional y por ello mismo se acentuarán cuestiones relativas al ámbito económico.

La inserción de América Latina en el contexto político mundial -y concretamente en el de la guerra fría, la distensión y el incierto panora-

${ }^{4}$ Conviene recordar que entre las "ilusiones perdidas" al respecto está una que compartió ampliamente mi generación: que la substitución de los regímenes capitalistas y su reemplazo por otros de cuño socialista extirparía los peligros de guerra entre - por lo menos- países afines a este segundo padrón. 
ma actual- tiene, como es obvio, perfiles propios. ${ }^{5}$ No es fácil su necesaria selección, tanto más cuanto resaltan notorias diferencias internas, a las que habrá que aludir sólo de pasada.

Así y todo, parece evidente que sobresale uno de carácter general, que constituye el marco principal de referencia para el examen. Parafraseando la sentencia de Porfirio Díaz, es el hecho de que "América Latina se encuentra tan lejos de Dios y tan cerca de Estados Unidos". En otras palabras, que la región se encuentra bajo la sombra omnipresente de una potencia hegemónica, que, además, es uno de los polos del pleito mundial.

Para entender el carácter de las llamadas - con cierto eufemismo"relaciones especiales" de Estados Unidos y América Latina conviene discernir tres planos sobresalientes, estrechamente vinculados y que se influyen mutuamente.

El primero es el de los nexos políticos strictu sensu, donde se enfrentan los designios y tácticas de la potencia dominante con las acciones y reacciones de los países de la región, disgregados como regla y que rara vez han logrado conjugar políticas de negociación o resistencia.

El segundo corresponde a los de carácter económico, también en su sentido específico, y que tiene que ver principalmente con el intercambio comercial, esto es, con la elevada representación del mercado del norte en las importaciones y exportaciones de nuestra región y la significación —-más cualitativa que cuantitativa- de América Latina para la economía estadounidense, como se destacará más adelante.

El tercer nivel privilegiado - en el cual se asocian los elementos económicos y los políticos-corresponde a la presencia de las empresas de Estados Unidos en la región, o sea a sus inversiones directas en diversos sectores, en los cuales suelen tener una gravitación dominante.

Desde cierto ángulo bịen podría decirse que en torno a esas dimensiones y a los conflictos que envuelven se plantean habitualmente los debates sobre imperialismo o anti-imperialismo, aspecto que se retomará más adelante.

En sí mismo, ese espectro de situaciones no discrepa mayormente del que podría encontrarse en otras áreas o países vinculados o dentro de la órbita global de Estados Unidos.

Sin embargo, también sobresalen diferencias sustantivas.

Una de ellas es la acusada incidencia de esos nexos y sobre todo el

${ }^{5} \mathrm{La}$ naturaleza de la inserción económica de la región ha sido un tema básico de la exploración teórica y concreta de la CEPAI y de su mentor, el Dr. Raúl Prebisch. En cierto modo, este trabajo enfoca otros aspectos de las relaciones Centro-Periferia. 
flagrante desequilibrio entre las partes que asocian. En ambos respectos, la condición latinoamericana (sin descuidar los contrastes nacionales) tiene relieves particulares bien conocidos, lo que nos excusa de abundar sobre ellos. Pero, lo que interesa más para este examen son las relaciones entre aquellos planos, sus ponderaciones relativas y sobre todo su entrecruzamiento. Desde esta perspectiva, creemos, se identifica mejor la especificidad de los vínculos entre América Latina y Estados Uñidos en el período cubierto.

Dentro del marco temporal elegido parece meridiana la primacía de los nexos políticos; y más concretamente, de la "lógica" de la pugna internacional. En principio, pues, los otros estarian claramente subordinados, a despecho de su evidente importancia.

Esta jerarquía, sin embargo, presenta rasgos particulares en América Latina, determinados fundamentalmente por el gran peso relativo de los inversionistas del país del norte. Nuestra hipótesis al respecto es que en ninguna de las áreas del mundo donde se proyecta la política norteamericana tiene una gravitación comparable la influencia de esos intereses.

Siendo evidente que la política exterior de Washington, en todos los lugares, responde en algún grado a las conveniencias y presiones de sus consorcios privados, parece cierto que en otras áreas - por ejemplo Europa o Asia- predomina la "macro-visión" política de sus intereses nacionales o, si se quiere, del conjunto de su complejo capitalista. En cambio, en América Latina, la "micro-visión" privada de las corporaciones más ligadas a la región ha tenido una significación desproporcionada en la política global del país del Norte.

Planteamos este criterio hace ya tiempo - a mediados de los años 60 - en algunos trabajos que trataban de examinar las razones de la perpetuación de los parámetros de la guerra fría en la región y el obstáculo que ello envolvía para los proyectos e iniciativas destinados a transformar sus estructuras económicas y sociales. ${ }^{6}$

- Para delinear el asunto - y por comodidad metodológica-vamos a imaginar dos escenarios alternativos, que ciertamente pecan de "reduccionismo" al dejar de mano matices y combinaciones. Grosso modo, uno predominó en los años de tajante guerra fría, esto es, entre el fin del conflicto mundial y las postrimerías del gobierno de Eisenhower en la década de los años 50. El otro — camino a la distensión- se insinúa

"La crisis latinoamericana y su marco externo", Revista Desarrollo Económico, Nos. 22-23, Argentina, diciembre, 1966; "Crítica del modelo político-económico de la izquierda oficial'" El Trimestre Económico, $N^{\circ} 121$, México, 1964. Ambos trabajos fueron reproducidos en Política y Desarrollo, Editorial Universitaria, Chile 1968. 
en esa coyuntura, se acentúa durante la administración Kennedy a principios de los años 60 (cuando se admite la "coexistencia pacífica") y se rubrica en tiempo de Nixon-Kissinger (cuando se habla explícitamente de distensión).

En el primero - en lo fundamental - la dimensión política propiamente tal no es afectada. En mayor o menor grado, las relaciones con Estados Unidos están nítidamente encuadradas en la matriz de la guerra fría y las diferencias de comportamientos nacionales- que las hay (por ejemplo en la Argentina de Perón o en la intervención en Guatemala en 1954) - no involucran un desafío de esa realidad y menos aún la posibilidad de un cambio de afiliación en el pleito de las grandes potencias.

Predominan, en consecuencia, las fricciones en los otros dos planos en la medida que las políticas de cambio en América Latina se centran en la expropiación de empresas o actividades de propiedad o bajo control norteamericano; en lograr condiciones y precios más favorables para las exportaciones; en mejores pautas de financiamiento o/y en diversificar los mercados de destino y origen del intercambio, incluso incorporando a los países socialistas.

Así y todo, la ausencia de reto político en el nivel general de los nexos con Estados Unidos no impidió su "politización" concreta. La potencia hegemónica desconfiaba de las implicaciones eventuales o a futuro de las mudanzas sobre el engranaje en la guerra fría o/y respecto a la seguridad y costo de sus abastecimientos. Pero al lado de ello - y predominando- sobresale la presión de los inversionistas afectados, que trataban por todos los medios a su alcance de fusionar su problema particular con el general de Estados Unidos; de identificar la amenaza contra sus intereses como una actual o potencial contra el balance político y destinada a servir al comunismo en última instancia.

Estas circunstancias, sin duda, conspiraron decisivamente para frustrar o mutilar los proyectos progresistas o nacionalistas de reforma en ese período. Ese reflejo inequivoco de la tensión externa dependió en lo principal - como se señaló en uno de los trabajos citados- de la envergadura y poder de presión de los intereses particulares perjudicados, de la significación de las actividades comprometidas para el abastecimiento actual o a futuro del país del norte y de los expedientes intentados para transferir los activos extranjeros al dominio nacional, ésto es, si se trataba de una confiscación, de alguna forma de expropiación o de una mera adquisición. ${ }^{7}$

'En "La crisis latinoamericana...", op. cit. 


\section{Las contradicciones de la distención}

En el segundo escenario de referencia, correspondiente a la fase posterior, no desaparecen los elementos mencionados, pero a ellos se agrega uno nuevo y primordial: la presencia de algunos proyectos de alteración del statu quo con un ingrediente político explícito de desafío de la hegemonia del país del norte e incluso de traslación al otro bando de la guerra fría. Este factor para a ser el dominante en esos casos, pero también acrecienta su influencia en otros más afines al anterior modelo.

Sobra decir que la experiencia de Cuba marca ese viraje y que señalar este hecho meridiano se presta a toda clase de malentendidos, deformaciones $-y$ hasta agresiones gratuitas. Es imprescindible, por éso, esclarecer ciertas cosas.

Desde luego, la hipótesis no involucra ninguna tomada de posición sobre ese fascinante episodio de la historia latinoamericana- y quizás el de mayor proyección mundial. Admiradores y críticos podrían compartirla sin que ello afectara sus inclinaciones básicas.

Resultaría asimismo absurdo interpretar lo dicho como que Cuba es responsable o "tiene la culpa" de haber inaugurado una nueva situación, aun más conflictiva que la anterior. La historia no se escribe de este modo.

Por otra parte, todavía está abierto el debate sobre si su afiliación al campo soviético fue producto de una deliberación anticipada o consecuencia de la presión de los negocios norteamericanos afectados por la revolución, factor siempre gravitante, como antes se destacó. ${ }^{8}$ Ponderando los términos del problema uno llega a pensar que dada la profunda, compleja y prolongada dependencia respecto al inmediato vecino del norte, la real alternativa que enfrentó fue la de hipotecar su designio de transformación radical dentro de ese marco o recurrir a la superpotencia rival como sostén del mismo. La suposición, claro está, abre otro debate respecto al acierto o desacierto de la elección, la

\footnotetext{
${ }^{8} \mathrm{Al}$ respecto puede considerarse esta penetrante reflexión de Herbert L. Matthews, "Dissent over Cuba", Encounter, julio de 1964: En política de los Estados Unidos no hay objeción de principio a la idea de que a veces las revoluciones son necesarias e inevitables. Las dificultades comienzan cuando algún personaje contradice fuertes y especificas ideas arraigadas o cuando una revolución implica, por ejemplo, la apropiación de bienes norteamericanos. La revolución de Bolivia, incluyendo la nacionalización de las minas de estaño (de propiedad local), despertó escasa repercusión o interés en los Estados Unidos en 1952. Pocos americanos supieron que una revolución estaba teniendo lugar en Bolivia, y no les habría importado aunque lo hubieran sabido. La revolución cubana dolió; sigue doliendo. Por eso es resentida".
} 
existencia o ausencia de otras opciones, etc. Pero no es ésta la oportunidad para seguirlo, tanto más que ahora tiene un interés estrictamente histórico.

Sea como fuere, aquel segundo aspecto, como adelantamos, es el que nos interesa reconsiderar, dada la vigencia siempre actual del problema y las mutaciones registradas en tiempos más recientes.

Lo que importa aquí es - como escribimos en un trabajo precitadoque "al ser derribado uno de los más carcomidos 'establecimientos' del área, no sólo tiene lugar una transformación de cuño socialista del sistema de poder y de propiedad sino que también ocurre un cambio de alineación en el esquema de guerra fría", lo que llevó a los Estados Unidos y a los grupos dominantes de la región "a identificar la revolución latinoamericana con un modelo determinado de cambio general: socialista marxista-leninista en lo interno; y adscrito al polo soviético en lo externo".9

Por lo demás, sería errado limitar el asunto a la experiencia de Cuba. Antes y después de su revolución, una parte significativa de la izquierda - la ortodoxa y los grupos más radicalizados- consideraron como ingrediente esencial de cualquier política consecuente de.transformaciones el antagonismo explícito no sólo con los intereses privados norteamericanos sino con Estadós Unidos como tal, o sea, como centro del sistema imperialista. Para la primera, aunque no siempre para los segundos, ello tenía como necesaria derivación el plegarse al otro bando de la guerra fría.

De ese modo, toda esa gama política estaba por la "internacionalización" del proceso de cambios nacionales, en tanto que otros (incluídas diversas fuerzas socialistas) se inclinaban más bien por la "internalización" de los conflictos emergentes, es decir, por escapar o disminuir la vinculación con la guerra fría y con las adscripciones a cualquiera de las superpotencias.

En resumen, parece evidente que el viraje cubano representó un salto cualitativo en todo este panorama, cuyos reflejos continúan gravitando - como es patente en la efervescencia centreamericana actual.

No es posible extender aquí el análisis a otros casos nácionales, como los de Chile y Perú, cuyos ensayos de transformación se agotan o colapsan dentro del cuadro de este período. También en ellos, como es patente, se registra el contrapunto y mutuas influencias de las acciones que afectan y antagonizan a los intereses privados y su proyección política vis a vis Estados Unidos y la pugna internacional. Anotemos

${ }^{9} \mathrm{En}$ "La crisis latinoamericana...", op. cit. 
sólamente que en ambas instancias -y seguramente asimilando la experiencia cubana - se trató de desvincular ambos planos e incluso las decisiones respecto a inversiones extranjeras fueron selectivas y hasta podría decirse pragmáticas ${ }^{10}$. Ello no impidió, sin embargo, aquella "internacionalización" de los procesos, aunque ésta fue mucho mayor en lo que respecta a Chile que al Perú, por razones - y con consecuencias- que sólo podrían repasarse en un análisis detenido que excede los linderos de estas notas y que han sido objeto de numerosos estudios y controversias.

Las relaciones y circunstancias descritas explican en gran medida por qué el tránsito hacia la fase de distensión internacional iniciada a fines de los años 50 reviste facetas tan contradictorias en América Latina.

Desde luego, el triunfo mismo de la revolución cubana dependió en medida significativa de esa realidad. Basta pensar en sus probabilidades de éxito en el auge de la guerra fría o incluso en las circunstancias actuales (años 1980-81) para comprender cuán importante fue esa incidencia.

Pero es igualmente meridiano que aquel período — consumada ya la victoria revolucionaria - resulta particularmente conflictivo en las relaciones del "gran vecino" con América Latina, aunque haya agudas diferencias al respecto entre sus países. La invasión de Bahía Cochinos y la crisis de los misiles en Cuba, la intervención en Santo Domingo y el auge de la doctrina y práctica de la "seguridad hemisférica" o nacional son testimonios elocuentes de lo señalado, sin perjuicio de la contracorriente reformista de la Alianza para el Progreso.

Por otra parte, a mediados de los años 60 se inaugura en Brasil el ciclo-de los regímenes llamados "burocrático-autoritarios", una de cuyas características primordiales es su radical anti-comunismo y su adscripción irrestricta al polo occidental, aunque ello no siempre haya significado consonancia con Estados Unidos en todos los planos, en especial en la administración Carter y a raíz de su insistencia en los derechos humanos y democráticos - aspecto, dicho sea de paso, que ha sido sistemáticamente ignorado o subestimado por la izquierda (ortodoxa y heterodoxa) a pesar de su importancia primordial en la segunda mitad de los años 70. Aquellos casos, ciertamente," no pueden considerarse como mero reflejo de la guerra fría aunque hayan significado la plena aplicación de las doctrinas sobre "seguridad nacional" disemina-

${ }^{10}$ En verdad, los sectores más radicalizados del espectro político consideraron esas políticas como "blandas" y reclamaron enfrentamientos tajantes con Estados Unidos y los intereses extranjeros. 
das desde el Pentágono. Factores endógenos de distintos signos y naturaleza tuvieron considerable y a veces decisiva importancia en su cristalización, aunque no es posible repasarlos aquí dada su complejidad y los contrastes nacionales ${ }^{11}$.

\section{Los cambios dentro de una distensión "conflictiva"}

Lo señalado no implica de ninguna manera que el período de distensión no haya tenido mayor importancia para América Latina o que sus modalidades futuras o interrupción sean indiferentes para la región. Para tener una visión más apropiada al respecto es útil pasar revista a distintos elementos, siguiendo los criterios de análisis antes propuestos.

En términos generales podría postularse que la presencia y gravitación de Estados Unidos ha disminuído y que, por oposición, se ha ampliado el margen de maniobra — v.gr., de independencia- de los países de la región.

No es fácil fundamentar cabalmente esta hipótesis. Muchos argumentos podrían levantarse en su contra, pero también hay algunos bastante sólidos a su favor, aunque ellos inciden principalmente sobre el plano económico. Como es inevitable, sólo podemos referirnos a los que creemos más significativos y en forma muy sumaria.

Desde luego, hay muchos que no han valorizado lo suficiente el extensivo proceso de nacionalización de actividades y empresas básicas que ha tenido lugar en la región en tiempos recientes y particularmente desde fines de los años 60 . Ha abarcado principalmente el campo de los productos primarios (petróleo y cobre, a la cabeza) y de los servicios públicos, esto es, de aquellos que en el pasado representaban el grueso - de las inversiones directas, extranjeras y el principal foco de tensiones.

Ese movimiento ha sido contrapesado por lo ocurrido en la industria y en las finanzas, donde se ha concentrado e incrementado la llamada "transnacionalización" 12 . Sin embargo, aun en estos campos, han ocurrido cambios notorios en los grados de tuición nácional y en relación a nuevas formas de compañía y compromisos con el sector público y los empresarios locales, configurándose en algunas partes lo que F. H. Cardoso ha denominado "un capitalismo asociado dependiente".

"Sobre el tema, entre muchos otros, sobresale la interesante colección de ensayos incluidos en el libro The New Authoritarianism in Latin America, Princeton University Press, New Jersey, Estados Unidos, 1979.

${ }^{12}$ Gracias a este desplazamiento, las inversiones directas de Estados Unidos continúan representando alrededor de la mitad del total radicado en la región. Véase al respecto, (:El'AL, Estudio Económico de América Latina, 1977, Tercera Parte. 
Cualquier sea el juicio que se tenga'sobre la naturaleza y àlcances de estas realidades, creemos que una perspectiva histórica llevaría a diagnosticar una menor supeditación respecto a los intereses foráneos que los cuadros "clásicos", del pasado, sobre todo si se valorizan la diversificación y ampliación de la plataforma productiva y otros elementos afines. Pero, otra vez, claro está, no podrían olvidarse las disparidades entre países en esta materia y la aparición y efectos todavia difíciles de calibrar, como el creciente endeudamiento con el capital financiero internacional.

Por otro lado, resulta evidente que los lazos comerciales y financieros oficiales con Estados Unidos han perdido significación relativa. Entre 1958-1962 y 1974-1978 (en promedio anual), por ejemplo, la representación de las importaciones désde Estados Unidos bajó de un $37 \%$ a un $26 \%$, a la vez que la de las exportaciones a ese país pasó de un $44.5 \%$ a un $26 \%$; y en lo que respecta a las corrientes de créditos fue reduciéndose la parte correspondiente a los estatales y tomando cuerpo la provista por la banca internacional, en la cual acrecentaron su importancia fuentes europeas y japonesas, aunque el papel de las norteamericanas continuó siendo dominante. De todos modos, conviene reiterar que América Latina continúa teniendo una importancia relevante como mercado y como abastecedor para Estados Unidos, aspecto que no puede descuidarse en esta discusión ${ }^{13}$.

En la dirección e intensidad de estos cambios $\rightarrow$ y de otros en el mismo sentido- ha influido sin duda el cuadro de la distensión. Al hacerse más flexible el marco de la guerra fría mejoraron las posibilidades de adoptar medidas que en las circunstancias anteriores habrian dado lugar a severos conflictos o incluso habrían sido imposibles. Sin embargo, es evidente que el mayor poder decisorio y negociador de: América Latina también debe vincularse a la erosión del sitial hegemónico del país del norte.

Sobra repetir lo mucho escrito y fundamentado al respecto. Solamente anotemos aquí que la pérdida relativa de su poder en diversos planos ha significado incrementar tanto el de sus rivales como el de sus

\footnotetext{
${ }^{13}$ Hacia fines de los años setenta (1978), la región proveía entre el 50 y más del $90 \%$ de las importaciones estadounidenses de azúcar, frutas, hortalizas, café, cacao, ganado, mineral de hierro y concentrados, bauxita y alúmina. La participación de México, éso sí, es primordial en los rubros perecibles. Asimismo, y respecto a la situación a fines de los años 60, que se habría fortalecido en el último tiempo, el mercado latinoamericano compraba por un valor superior a las ventas de Estados Unidos a la Comunidad Europea. Véase, A. Pinto, "Economic Relations Between Latin America and the United States: Some Implications and Perspectives", en Latin America and the United States: The Changing Political Realities, Stanford University Press, Stanford, California, 1974.
} 
amigos. Al reaparecer o fortalecerse la presencia europea y japonesa (sin olvidar a Canadá y más recientemente a los países petroleros y a varios de Asia), América Latina encontró otros refuerzos para políticas alternativas vis a vis Estados Unidos. Y lo propio ha sucedido respecto al universo socialista, aspecto que sí puede inscribirse derechamente entre las consecuencias de la distensión.

En este último aspecto es útil recordar el rápido aumento de un intercambio que hace unos veinte años era insignificante. Las exportaciones de América Latina (excluyendo a Cuba) hacia la Europa Oriental, en 1960, llegaban apenas a 160 millones de dólares. En 1976-1977 alcanzaron a unos 1.600 millones por año. Las importaciones desde esa área, éso sí, sólo crecieron dé unos 150 millones a 700 millones en $1977^{14}$. Por otro lado, también empieza a percibirse la participación de China, que en parte se explica por la lógica de su propia guerra fría con la uRss.

La referencia a las grandes potencias socialistas induce a destacar otro aspecto sobresaliente del período de distensión. La querella sinosoviética y los consecuentes reajustes internacionales redujeron substancialmente la simplicidad del enfrentamiento Este-Oeste. Complicaron las posturas anti-comunistas de un lado y los frentes antiimperialistas del otro, desdibujando las definiciones polares a ultranza del pasado. En cierto modo - siguiendo el criterio del profesor Medina Echavarría- obraron en favor de la "des-satelización" y la "descentralización ideológica", aunque, claro está, introduciendo otros elementos perturbadores que en algunos casos han llegado a lo caricaturesco como el apoyo o compromiso de una u otra potencia socialista a régimenes dictatoriales latinoamericanos.

La recapitulación de los elementos privilegiados confirman el carácter contradictorio del período de distensión en lo que respecta a América Latina. Dicho de otra manera, parecería válida la hipótesis de que el cambio de escenario tuvo menor relieve y significación que en otras áreas - y principalmente en lo que se refiere a las propias relaciones entre las grandes potencias capitalistas y socialistas. No se habría llegado, pues, en América Latina, a una modificación esencial del marco anterior o, por lo menos, según las cạtegorías de don José, se estaría más cerca de la "distensión conflictiva" que de las otras acepciones ${ }^{15}$.

${ }^{14}$ Las importaciones desde Cuba alcanzaron a poco menos de 3.000 millones de dólares en 1977 y las exportaciones a ese país, casi 2.700 millones. C:EPAL, Relaciones entre América Latina y países miembros del Consejo de Asistencia Mutua Económica (CAME), E/CEP'AL/G. 1104, mayo, 1980.

${ }^{15}$ Huelga señalar que la crisis reciente del "viejo orden" en Centroamérica levanta incógnitas sobrecogedoras en la materia, que no es posible desentrañar en este momento. 
Así y todo, para quienes vivieron las vicisitudes y restricciones de todo orden que importó la fase de franca guerra fría, la diferencia continúa siendo manifiesta y trascendental.

\section{Dispersión y conciertos latinoamericanos}

Para cerrar esta nota queremos enfocar algunos aspectos atinentes a la realidad política latinoamericana y algunas situaciones diferenciales dentro de la región.

El primero se inspira en otra de las preocupaciones dominantes de don José: "la descomposición del gran cuerpo histórico hispánico" y el hecho de que "los estados desunidos de Sudamérica se hubieran dado como tales aunque no sé hubiera producido la fragmentación del cuerpo hispánico en la forma que se hizo". Es "el tema de la integración - el de la reunificación de la totalidad perdida".

Yendo derecho al meollo del asunto cabría preguntarse sobre la evolución del "cuerpo político" latinoamericano a lo largo de las fases distinguidas, ya que éste no es un ente pasivo en los procesos analizados. Aquí también afloran contrastes llamativos e importantes, aunque la presentación esquemática puede exagerarlos y descuidar su complejidad.

En el período de franca guerra fría, la estructura de las relaciones políticas Estados Unidos-América Latina es perfectamente diáfana y se expresa institucionalmente en la OEA, donde conviven desequilibradamente la grande y dominante potencia del norte y los dispersos estados del sur. Este esquema global se combina con eslabones bilaterales entre Estados Unidos y cada país, cuyo contenido está dictado por los balances de poder e intereses envueltos en cada caso.

En la fase que se asocia con la distensión -y particularmente hacia fines de los años 60 - junto al debilitamiento de la OEA como instrumento de aglutinación y, sobre todo, de transmisión de las políticas de Estados Unidos, aflora el fenómeno que se llamó del "consenso latinoamericano", que llegó a formalizarse en el CECLA y que había sido estimulado por la fugaz promoción de la Alianza para el Progreso por parte de la administración Kennedy ${ }^{16}$.

Esos también son los años en que avanzan las iniciativas sobre integración económica, resistidas por el país del norte en la etapa de su concepción y primeros pasos — básicamente por la hostilidad de sus intereses privados-y que después van-siendo progresivamente tolera-

${ }^{16}$ CECLA. Comisión Especial de Coordinación Latinoamericana. 
das y hasta estimuladas cuando Washington valoriza la fuerza del impulso y sus eventuales reflejos positivos sobre el desarrollo y la estabilidad política regionales.

Esta evolución paralela y complementaria se interrumpe en gran medida a lo largo de los años 70 . Inciden en ésto los elementos políticos examinados antes y el fraccionamiento consiguiente de las asociaciones formales c informales entre paises latinoamericanos a causa del retroceso democrático en varios de ellos. De hecho, desaparece cualquier agente de negociación colectiva con la potencia del Norte, aunque no se interrumpe el ocaso del viejo rol de la OEA.

Eso sí, emerge el SELA (Sistema Económico Latinoamericano) como embrión promisorio aunque todavía incipiente y el Pacto Andino, a despecho del insólito retiro de Chile y de las dificultades para materializar sus proyectos integradores, adquirió un relieve político inesperado.

Es evidente que estas cuestiones tienen significación primordial para la colocación de América Latina en los escenarios de la guerra fría y la distensión. Más aún -y aunque ésto parezca una suposición demasiado optimista - también lo es para que ella pudiera ejercer alguna influencia sobre sus cambios o tendencias generales. En otras palabras, los progresos en el consenso político-externo y en la articulación económica interna de la región son fundamentales para determinar su posición - activa, pasiva o refleja-y, su capacidad de negociación e influencia respecto a Estados Unidos y el contexto internacional.

Naturalmente, esta apreciación general tiene muy distintas traducciones si se consideran las realidades nacionales.

En general, los países mayores y algunos intermedios - por razones evidentes y diversas - han adquirido una capacidad negociadora que les permite sortear los dilemas extremos de la guerra fría o la distensión conflictiva e incluso seguir políticas de contrapeso (y aprovechamiento propio) de las rivalidades interpotencias. Otros, a la inversa, se encuentran todavía en condiciones mucho más restrictivas y expuestos a elecciones que comprometen sus aspiraciones de mayor autonomía.

Es evidente que para los segundos tiene importancia vital la posibilidad de acciones comunes o coincidentes entre ellos y más aún con los de mayor peso específico, pero ello no significa que la cuestión sea insignificante para los últimos. En este sentido resulta sugestivo el creciente interés de Brasil en sus lazos latinoamericanos - dictado más por sus necesidades económicas que por la vocación "subimperialista" que se elucubró en algunas divagaciones ideológicas.

Por otra parte, el imperativo de la articulación regional trasciende 
más allá del marco hemisférico y debe inscribirse en la estrategia global del Tercer Múndo, esto es, en las relaciones Norte-Sur.

Cualesquiera sean las particularidades de la condición latinoamericana vis a vis o dentro del universo de la Periferia -que sin duda son meridianas-, la experiencia ha sido porfiada en demostrar que las posibilidades de negociación razonable con las economías centrales dependen en alto grado de la coherencia de aquel conjunto y de la consiguiente multiplicación de sus esfuerzos aislados.

Pero aquí interesa la proyección del asunto sobre la cuestión política que se discute. Como se desprende de uno de los juicios antes citados del profesor Medina Echavarría (véase página ) existe una vinculación transparente entre la tensión Este-Oeste y la Norte-Sur. En la medida que se agudiza la primera sucede lo mismo con la segunda por sus derivaciones económicas y políticas. Las posibilidades de cooperación se reducen y las exigencias de afiliación se acrecientan.

Por desgracia, con el movimiento de los no-alineados ha ocurrido algo similar a lo registrado en el medio político latinoamericano. Se ha diluido su identidad y también su fuerza. Sin embargo la razón de su existencia y acción continúa vigente, tanto más si los horizontes de la distensión se oscurecen. Dispersos y sin oportunidad de ejercer una influencia moderadora y que promueva sus intereses, quedan expuestos a un reclutamiento que ya demostró el pasado de la guerra fría que no opera a su favor. Aunque es cierto que la fragmentación mayor o menor de los grandes polos ha reducido la fuerza de convocatoria de las superpotencias, no pueden subestimarse las tendencias contrarias que desataría un enardecimiento de la pugna —en particular en áreas determinadas, como la propia América Latina.

Sea como fuere, al cerrar estas notas nos parece útil volver sobre la idea expresada anteriormente (página ) sobre la relación entre los procesos de transformación en los países latinoamericanos y el marco de la pugna mundial. La hipótesis general al respecto es que conviene a los primeros "internalizar" sus conflictos inevitables y no "internacionalizarlos", esto es, no asociarlos con una afiliación irrestrictá con alguno de los grandes bloques o superpotencias.

No es posible repasar aquí los principales argumentos que podrían fundamentar o rebatir ese planteamiento. Como es meridiano, por lo demás, sólo podría realizarse ese ejercicio a la vista de situaciones concretas de lugar y coyunturas y teniendo en cuenta que las orientaciones nacionales al respecto estarán necesaria - y a veces decisivamente-condicionadas por las acciones y reacciones de las potencias hegemónicas. 
Sin embargo, pueden tomarse como base de sustentación de aquella hipótesis una realidad general ya destacada y algunas ilustraciones concretas.

Lo primero se refiere al hecho manifiesto de la "desconcentración" al interior de los polos este-oeste (o capitalista y socialista) y la consiguiente ampliación del radio de maniobra (la "des-satelización" real o potencial) que ello significa para los demás países. Podría aducirse con razón que la particular colocación, geopolítica de América Latina (ya comentada) respecto a Estados Unidos disminuye esa repercusión, sobre todo en lo que respecta a los que - por una y otras razonestienen menor poder de negociación, pero éso no desmiente que aun para éstos se ha modificado el cuadro pretérito ${ }^{17}$.

Desde el otro ángulo y teniendo a la yista el campo socialista, poco considerado en este tipo de análisis, no deberían menospreciarse casos sugerentes como el de Yugoeslavia, cuya particular variante socialista -que tanta resistencia y agresividad suscitó en sus comienzos por parte de la URSS y sus acólitos- a la postre escapó del dilema tajante del compromiso en la guerra fría. Y se podrían agregar otras especies peculiares como la de Rumania y Finlandia y ahora, quizás, Polonia ${ }^{18}$

Aun si se es por completo pesimista en esta materia, poca duda cabe de que la alternativa a la orientación planteada (la afiliación deliberada y explícita a la superpotencia rival) abre todo un espectro de dificultades y sacrificios que bien vale la pena empeñarse en evitar.

De todos modos, valga recalcar que estos cursos se encuentran supeditados en alto grado a las tendencias del pleito internacional. Si éste se enardece, pierde fuerza nuestra proposición, aunque los elementos estructurales relevados no desaparezcan. A la inversa, ella se robustece si la distensión se asienta o progresa, si bien ésto no eliminará los fermentos de conflicto.

$* \quad * \quad *$

${ }^{17}$ Aunque inconcluso e incierto (mediados de 1980), el caso de Nicaragua por lo menos ha dejado en evidencia posibilidades de colaboración de países capitalistas desarrollados (incluso el propio Estados Unidos) y de América Latina (Costa Rica y Venezuela, particularmente) que no se presentaron en la experiencia de Cuba. La propia actitud de Estados Unidos -o si se quiere, de la administración Carter- fue muy diferente y pecaría de sectario quien lo negara. El futuro, claro está, puede escribir otra historia, pero en ella también influirá la opción de Nicaragua en política exterior.

${ }^{18}$ Inevitablemente se recordará el caso actual de Afganistán, cuyos rasgos específicos no es posible examinar aquí, pero no creemos que cancele la formulación general. 
Pero conviene poner fin a estas especulaciones. Volviendo a don José, sólo cabría recordar que estos desafíos apremiantes nos urgen a hacer lo que podamos y debamos para lograr un "modelo mínimo de paz", adecuado a los problemas de nuestro tiempo "en que aparezcan atenuadas, recíprocamente moderadas al menos, las desnudas relaciones de poderío que mantienen su obediencia a la ley de la selva en el escenario internacional". 